\title{
FATORES MULTINÍVEIS DA TRAJETÓRIA INOVADORA DA VITIVINICULTURA NA CAMPANHA GAÚCHA
}

\author{
Luciana Rochedo Spencer dos Santos* \\ Marcelo Fernandes Pacheco Dias**
}

RESUMO: O trabalho apresentado tem como objetivo analisar os fatores sociotécnicos que contribuem para a trajetória inovadora da produção vitivinícola na Campanha Gaúcha. Dentro de uma análise de transição utiliza-se a abordagem teórica da perspectiva multinível (PMN) para se compreender a adoção da vitivinicultura, através de um estudo de caso de uma região que tem recebido destaque pela produção de vitis viniferas. Para atender aos objetivos da pesquisa realizou-se a investigação em duas etapas. A etapa A definiu as três fases da vitivinicultura na região, a primeira de 1887 a 1969 (Experimentação), a segunda de 1970 a 1999 (Estabilização) e a terceira de 2000 aos dias atuais (Resistência). Na etapa B foram identificados os fatores sociotécnicos, suas combinações e como evoluem ao longo do tempo. No intuito de somar esforços à teoria já existente em estudos de transição foram feitas duas proposições. A primeira proposição refere-se à inclusão de fatores no nível do regime denominados de potencial estruturante, especificidades da demanda e dinamismo da produção do conhecimento; e a segunda proposição corresponde à inclusão de fatores no nível do nicho denominados de identificação de oportunidades e ameaças, aproveitamento das oportunidades, reconfiguração, condições promotoras e barreiras. Foram identificados novos fatores que foram associados à ideia de recursos, sendo incluídos no nível da paisagem e do nicho. Ambas as proposições foram confirmadas.

PALAVRAS-CHAVE: Campanha Gaúcha; Perspectiva Multinível; Transição; Vitivinicultura.

\section{MULTI-LEVEL FACTORS OF THE INNOVATORY TRAJECTORY OF VITIVINICULTURE IN THE CAMPANHA GAÚCHA}

ABSTRACT: Socio-technical factors that contribute towards an innovating trajectory

\footnotetext{
Mestre em Desenvolvimento Territorial e Sistemas Agroindustriais pelo Programa de Pós-graduação em Desenvolvimento Territorial e Sistemas Agroindustriais da Universidade Federal de Pelotas (UFPEL), RS, BRASIL. E-mail: lucianarspencer@gmail.com

* Doutor em Agronegócio pela Universidade Federal do Rio Grande do Sul (UFRGS). Docente permanente do Programa de Pós-graduação em Desenvolvimento Territorial e Sistemas Agroindustriais da Universidade Federal de Pelotas (UFPEL), RS, BRASIL.
} 
in vitiviniculture production in the Campanha Gaúcha are analyzed. The multilevel perspective theoretical approach within a transition analysis is employed to understand the establishment of vitiviniculture. The case study of a region highlighted for its production of Vitis viniferas is forwarded. Investigation consists of two stages. Stage A defines the three phases of vitiviniculture in the region between 1887 and 1969 (experimentation), between 1970 and 1999 (stabilization) and between 2000 up to the present (resistance). Stage 2 identified the socio-technical factors and their combinations and the manner they developed over time. Two proposals were suggested to combine effort to theory within transition studies. The first proposal comprises the inclusion of factors, at regime level, called structuring potential, specific demand and production dynamism of knowledge; the second proposal corresponds to inclusion of factors at niche level called identification of opportunities and menaces, harnessing of opportunities, reconfiguration, promoting conditions and barriers. The new factors were associated with resources and included at landscape and niche level. The two proposals were confirmed.

KEY WORDS: Campanha Gaúcha; multi-level perspective; Transition; Vitiviniculture.

\section{INTRODUÇÃO}

$\mathrm{Na}$ literatura, transição tecnológica é um processo coevolucionário que se estende por décadas e envolve distintos atores e grupos sociais. A análise de uma transição tecnológica, sob uma perspectiva especial, pode ser aplicada como transição sociotécnica e, sob essa concepção específica, a tecnologia só tem efeito em conjunto com a ação humana, com as estruturas sociais e as organizações. A partir disso, quando ocorre uma transição, essa não envolve apenas a mudança de uma tecnologia para outra, mas também mudanças em outros elementos como regulamentações, infraestruturas, padrões culturais etc (GEELS, 2002). A transição sociotécnica envolve mudanças de longo alcance através de diferentes dimensões: tecnológica, material, organizacional, institucional, política, econômica e sociocultural (MARKARD; RAVEN; TRUFFER, 2012).

O framework PMN recebe a atenção de muitos estudiosos. A utilidade da PMN tem sido ilustrada em muitos estudos de casos históricos de transições tais 
como transporte (GEELS, 2005), navegação (GEELS, 2002), movimentação de carga (VAN DRIEL; SCHOT, 2005) e outros. O framework PMN também é aplicado em estudos contemporâneos associados à sustentabilidade, como por exemplo, em sistemas elétricos (VERBONG; GEELS, 2007; 2010; HOFMAN; ELZEN, 2010), mobilidade e "carros verdes" (NYKVIST; WHITMARH, 2008; GEELS, 2011), biogás e cocombustão (RAVEN, 2004) e moradia sustentável (SMITH, 2007). Outros estudos estão associados ao agronegócio, como alimentos orgânicos (SMITH, 2007) e bem-estar animal (ELZEN et al., ano; GEELS, 2011). Os estudos não se encerram diante desses mencionados.

No Brasil, mais recentemente, há alguns trabalhos que utilizam oframework PMN, em temas como novidades desenvolvidas por agricultores na produção ecológica de plantas medicinais (MARQUES, 2009), em estudo sobre o manejo de sistemas agroflorestais (BULHÕES, 2011), bem como sobre trajetórias dos bioplásticos (OROSKI, 2013), sustentabilidade de sistemas agroindustriais (MENDONÇA, 2015), desenvolvimento rural em comunidades de pecuaristas familiares (NICOLA, 2015), processo de transição dos recursos fósseis por matérias-primas renováveis (TORRES et al., 2015) e outros.

Em uma breve descrição do framework PMN, destaca-se que a abordagem parte do princípio que as transições sociotécnicas são processos não lineares que coevoluem e decorrem de interações multidimensionais entre indústria, tecnologia, mercados, política, cultura e sociedade civil. Tal perspectiva direciona para três níveis de análise: do nicho, do regime e da paisagem. Tais níveis são melhores descritos na seção a seguir.

Vê-se nos estudos de transição sociotécnica, em especial através do framework PMN, a possibilidade de se avaliar com mais amplitude distintos contextos sociotécnicos e suas configurações. Compreende-se que uma análise adequada de transição possa contribuir com esforços de gestão e que isso influencie positivamente a estruturação e continuidade de processos de transformação.

Embora já existam estudos de transição no ambiente do agronegócio, esses não correspondem à maioria dos trabalhos. Sugere-se que a abordagem teórica das "Transições Sociotécnicas" possa ser aplicada em um contexto distinto daqueles apresentados com maior frequência até a atualidade, em geral em pesquisas de 
sustentabilidade. Não obstante, em termos teóricos, atualmente há uma lacuna nos estudos de transição que se concentram no fato de compreender quais são os fatores ou elementos, ou a combinação desses, que favorecem a adoção de uma tecnologia, ou conduzem à inovação tecnológica. Para corroborar esta afirmação Genus e Coles (2008) afirmam que a PMN poderia ser aplicada de forma mais abrangente e de maneira sistemática, através da investigação do complexo de fatores que limitam ou propiciam a transformação e inserção das tecnologias em sociedade. Eles entendem que isso além de operacionalizar a PMN pode tornar as explicações feitas em seu nome, sobre transições, mais aceitas.

Assim sendo, o presente estudo se propõe à sistematização dos elementos encontrados nos três níveis a partir dos estudos realizados com a abordagem PMN e a avaliação de novos elementos nos níveis de nicho e regime a partir do estudo teórico sobre Dinâmica da Inovação de Dias, Pedrozo e Silva (2014). O presente artigo parte da premissa de que a abordagem teórica das "Transições Sociotécnicas" pode contribuir para a compreensão sobre como ocorreu a trajetória inovadora da produção vitivinícola na Campanha Gaúcha, que aponte os fatores envolvidos e como eles se combinam nesse processo.

Há distintos indicativos sobre a adoção da vitivinicultura na Campanha, dentre eles um que se destaca é o esgotamento fundiário na Serra Gaúcha. Tal região, tradicional na produção de uvas, buscou em outras terras a competitividade em termos de qualidade de produção. Recorreu também a espaços economicamente mais viáveis, em razão dos valores imobiliários elevados em seu espaço, pela demanda rural e pela exploração de outras atividades econômicas como o turismo (FALCADE, 2011). Associado a isso já era notória a qualidade das terras da Campanha desde a década de 1970, que demarca o período de exploração comercial da vitivinicultura na região, em especial pelas condições edafoclimáticas que dão origem a excelentes frutos que se traduzem em vinhos de qualidade.

Com a necessidade de compreensão dos fatores condicionantes da trajetória inovadora da produção vitivinícola da Campanha Gaúcha, tem-se a seguinte questão de pesquisa: Quais os fatores sociotécnicos que contribuem para a trajetória inovadora da produção vitivinícola na Campanha Gaúcha? E, assim sendo, tem-se como objetivo analisar os fatores sociotécnicos que contribuem para a trajetória 
inovadora da produção vitivinícola na Campanha Gaúcha.

De forma a conferir organicidade ao presente artigo, na seção 2 há uma breve discussão do framework PMN; na seção 3 é apresentado o método da pesquisa; na seção 4 são indicados os resultados; e na seção 5 são apontadas as considerações finais.

\section{FRAMEWORK PMN}

A PMN foi inicialmente desenvolvida pela Universidade de Twente, na Holanda, por Arie Rip, René Kempe Johan Schot. Posteriormente foram somados esforços por parte de Frank Geels através de seus artigos individuais e em parceria com outros autores como Schot e Rip (VAN DRIEL; SCHOT, 2005). Nessa perspectiva se distinguem três níveis de conceitos analíticos, que são: regime (o lócus das práticas estabelecidas e das regras que estabilizam o sistema), nicho (lócus das inovações radicais) e paisagem (exógeno ao regime) (GEELS, 2011).

O nível do regime sociotécnico foi inicialmente descrito como domínio de práticas, regras e pressupostos compartilhados (ROOTMANS et al., 2001), ou ainda, cultura, estrutura e práticas dominantes (LOORBACH, 2007). O conceito refere-se a uma extensão do conceito de regime tecnológico de Nelson e Winter (1982), definido como um conjunto de rotinas cognitivas participadas em uma comunidade de engenheiros (GEELS; SCHOT, 2007). Sociólogos ampliaram este conceito argumentando que cientistas, políticos, usuários e grupos de interesse também contribuem para o desenvolvimento tecnológico (BIJKER, 1995).

Mais recentemente, o regime sociotécnico foi definido como um conjunto semicoerente de regras que orientam e coordenam as atividades de grupos sociais que reproduzem os vários elementos dos sistemas sociotécnicos. Mais especificamente, o regime sociotécnico é definido como um conceito analítico interpretativo intangível que está por trás das atividades reproduzidas pelos atores e que reproduzem um sistema de elementos tangíveis (GEELS, 2011).

Considera-se que o regime é algo que se estabelece e vigora em determinado tempo e espaço, formado por esses elementos tangíveis e intangíveis. Sendo que 
os elementos intangíveis se referem às crenças, heurísticas, rotinas, modos padronizados de fazer as coisas, paradigmas políticos, visões, promessas, expectativas sociais dos atores. Já os elementos tangíveis observáveis podem ser: 1) infraestrutura, 2) artefatos, 3) atuação no mercado, como em rede de produtores; redes industriais; de fornecedores (de materiais, de componentes, de máquinas); 4) regulamentações como: 4.1) regras envolvidas (leis, contratos, regulações, regulamentos, normas) oriundas de autoridades públicas (Ministérios Nacionais, Comissão Europeia); 4.2) regras de stakebolders: de Grupo de usuários; Grupos sociais; oriundas de rede financeira (fornecedor de capital de risco, empresa de seguros). Além dessas quatro, foi destacada também a participação de rede de pesquisa (universidades, institutos técnicos) (GEELS, 2002; 2011).

Ao revisar teoricamente os fatores que afetam o nível do regime, alguns autores (MILLER; FLORICEL, 2007; DIAS; PEDROZO; SILVA, 2014) também encontraram elementos de pressão que denominaram como especificidades da demanda do mercado, potencial estruturante e dinamismo da produção do conhecimento. Sendo que as especificidades da demanda referem-se a pressões advindas de produtos ou serviços com aplicações complexas, que podem ser produtos ou serviços utilizados por grandes firmas ou governos; esta especificidade da demanda pode se referir também a produtos ou serviços não críticos, que se referem àqueles direcionados a consumidores comuns. Em relação ao potencial estruturante, este é formado por um conjunto de pressões provenientes de regulamentações e normas como legislação específica ou políticas públicas, entre outras, como também das normas que envolvem os stakeholders e a dominância tecnológica. O terceiro elemento de pressão está relacionado ao dinamismo da produção do conhecimento, ou seja, este se refere aos fluxos de informações novas e amplas ao redor de diferentes informações; aos fluxos de informações novas, porém ao redor das mesmas aplicações; ou ainda, aos fluxos de informações produzidas a partir da experiência com os produtos existentes, ao aprimoramento.

A partir disso fez-se a proposição 1: Os fatores associados ao nível do regime envolvem além de infraestrutura e artefatos elementos como potencial estruturante, especificidades da demanda e dinamismo da produção do conhecimento.

O nível do nicho sociotécnico é onde as inovações radicais aparecem. 
Pode ser um pequeno nicho de mercado, ou ter a forma de nichos tecnológicos, projetos de P\&D, ou ainda projetos experimentais. Envolvem atores heterogêneos, como utilizadores, produtores, autoridades públicas e outros (GEELS, 2005). As novidades são inicialmente configurações sociotécnicas instáveis com baixa performance (GEELS; SCHOT, 2007). As inovações ocorrem como práticas locais e formam nichos quando uma rede de atores compartilha expectativas em torno da novidade e investem em seu desenvolvimento (HOFMAN; ELZEN, 2010). Os atores, tais como empreendedores, startups, spin-offs, trabalham em inovações radicais que se desviam dos regimes existentes, onde os usuários têm demandas especiais e estão desejosos por suporte para inovações emergentes (GEELS, 2011). Os nichos são também frequentemente descritos como espaços onde as atividades inovadoras se estabelecem e onde há proteção contra as regras de seleção dominantes (LACHMAN, 2013). Consequentemente nichos agem como espaços de incubação de inovação protegidas contra a seleção do mercado. Por isso são mais flexíveis, são locais de aprendizado para tecnologia, preferências do usuário, regulamentos, infraestrutura e significado simbólico (GEELS, 2005).

De acordo com Geels (2005), sociólogos da tecnologia têm destacado a relevância dos processos sócio-cognitivos, como o acúmulo de redes sociais em nichos e de coordenação de atividades por regras e percepções. Acrescenta as instabilidades nas redes sociais, pois são pequenas, com regras imprecisas e com atores trabalhando em direções distintas. Os nichos podem ser conduzidos e desenvolvidos por essas pequenas redes de atores dedicados, geralmente atores que estão fora do regime (GEELS; SCHOT, 2007; LACHMAN, 2013). Os atores do nicho esperam que suas novidades sejam utilizadas no regime ou até substituam atividades desse regime. Isto não é fácil, porque o regime é estabilizado por muitos mecanismos de proteção e porque os nichos podem ter um desajuste com as dimensões existentes do regime, como, por exemplo, de infraestrutura apropriada, regulações e práticas dos consumidores. Os nichos são cruciais para as transições porque eles provêm as sementes para a mudança sistemática (GEELS, 2011).

Apesar de se destacar a importância do nicho, pouco tem sido referenciado sobre quais são as atividades, condições promotoras e barreiras que estão associadas a este nível de análise da transição sociotécnica. Cita-se a necessidade de se conside- 
rar as instituições, organizações e redes de atores (GEELS, 2005; 2011).

A partir de uma revisão do campo da inovação (NONAKA; TAKEUCHI, 1995; MILLER; FLORICEL, 2007; TEECE, 2007; NONAKA; TAKEUCHI, 2008) os autores (DIAS; PEDROZO; SILVA, 2014) identificaram um conjunto de atividades que dão suporte ao processo de inovação das organizações e que por ser associada às organizações podem ser consideradas no nível do nicho. Os autores (DIAS; PEDROZO; SILVA, 2014) dividiram estas atividades em identificação de oportunidades e ameaças, aproveitamento das oportunidades e reconfiguração do que for necessário para ajuste e manutenção dos negócios.

As atividades de identificação de oportunidades e ameaças podem se dar através do desenvolvimento de atividades organizacionais com objetivo de: descobrir, interagir e avaliar informações sobre as expectativas dos clientes; dos centros de produção de ciência e tecnologia; dos fornecedores; do ambiente interno das empresas e setores de P\&D; da participação em redes (MILLER; FLORICEL, 2007; TEECE, 2007; DIAS; PEDROZO; SILVA, 2014).

As atividades de aproveitamento das oportunidades envolvem ações como entendimento sobre a apropriabilidade do conhecimento desejado, conhecimento do posicionamento das organizações mais inovadoras, fomento à criatividade, desenvolvimento de novos produtos e serviços, gerenciamento da arquitetura dos produtos existentes, conhecimento e gestão da complementaridade de ativos, avaliação das atividades atuais desenvolvidas (MILLER; FLORICEL, 2007; TEECE, 2007; DIAS; PEDROZO; SILVA, 2014).

As atividades de reconfiguração envolvem descentralização das decisões, governança das ações, práticas de transferência e proteção do know-bow e coespecialização, definido como combinação de ativos para proteger o valor (MILLER; FLORICEL, 2007; TEECE, 2007; DIAS; PEDROZO; SILVA, 2014).

Segundo Dias et al. (2014) estas atividades são favorecidas ou não por condições promotoras e barreiras. As barreiras podem ser individuais, organizacionais e externas. As barreiras individuais são compostas por acomodação e ameaça à autoimagem (NONAKA; TAKEUCHI, 2008). As barreiras organizacionais são compostas por falta de exposição ao conhecimento diverso e complementar, experiência passada, falta de mecanismos sociais de integração (ZAHRA; GEORGE, 2002). As barreiras 
externas podem estar relacionadas à presença de regimes de apropriação (ZAHRA; GEORGE, 2002). As condições promotoras podem ser fomento à autonomia, flutuação e caos criativo, redundância e variedade (NONAKA; TAKEUCHI, 2008).

Assim sendo, foi elaborada a proposição 2: Os fatores associados ao nível do nicho envolvem atividades de identificação de oportunidades e ameaças, de aproveitamento das oportunidades, de reconfiguração, condições promotoras e barreiras.

O terceiro nível, da paisagem sociotécnica, inclui fatores mais amplos que envolvem eventos ou desenvolvimentos com grande influência no crescimento tecnológico (RAVEN, 2004), ou ainda, formam um contexto externo que os atores do regime não podem influenciar no curto prazo (VAN DRIEL; SCHOT, 2005). As mudanças nesse nível geralmente demoram décadas.

A paisagem sociotécnica forma um ambiente exógeno para além da influência direta do nicho e do regime de atores (GEELS; SCHOT, 2007). Nichos e regimes influenciam pouco no nível da paisagem que representa o todo, o conjunto de impactos fora do nível do regime e do nicho, como tendências e eventos globais, nos quais influenciam os níveis abaixo (LACHMAN, 2013). Este nível é visto como residual, pois pode incluir muitos tipos de influências (GEELS, 2011). A paisagem sociotécnica influencia o nível do regime e do nicho (GEELS; SCHOT, 2007) e seus fatores podem afetá-los significantemente e até mesmo resultar em mudanças nesses níveis (LACHMAN, 2013).

Alguns desses fatores presentes no nível da paisagem podem incluir tendências demográficas (envelhecimento da população, êxodo rural), ideologias políticas (mudanças partidárias), valores sociais (preocupações ambientais), padrões macroeconômicos, como flutuações no preço do petróleo, recessão econômica, privatizações, cortes em investimentos (VAN DRIEL; SCHOT, 2005; GEELS, 2011); padrões culturais profundos, desenvolvimento macro político (GEELS; SCHOT, 2007); eventos repentinos, com grandes impactos (intempéries climáticas: vendavais, furacões, secas etc. ou guerras).

A perspectiva multinível argumenta que as transições ocorrem através da interação entre os três níveis e que o alinhamento destes possibilita o avanço das novidades sobre a inovação dominante no mercado (GEELS; SCHOT, 2007). Nichos e regimes influenciam através de ações técnicas e econômicas, como trocas 
de materiais, investimentos em pesquisa e desenvolvimento, coalizões estratégicas, lutas de poder e competição, contudo o regime tende a ter mais força sobre o nicho (GEELS; SCHOT, 2007). O reforço entre os três níveis pode criar uma janela de oportunidade. Os fatores da paisagem podem criar um desacordo enquanto os nichos podem conquistar uma oportunidade para uma posição central dentro do sistema (LACHMAN, 2013).

Para Geels (2005) as transições acontecem através da interação entre os processos em diferentes níveis da PMN. Ele distingue quatro fases em transição, que são: experimentação, estabilização, resistência e substituição.

$\mathrm{Na}$ fase de experimentação, ou primeira fase, surgem dos nichos inovações radicais, que estão fora ou à margem do regime existente. Essa rede, ainda sem ligações consistentes, é instável, pois não existem regras com uma concepção clara e dominante. Limitadas e precárias, improvisam e se envolvem em experimentos. Pode haver várias novidades competindo umas com as outras e os atores procuram identificar as necessidades dos usuários. Nesse momento, as inovações não representam uma ameaça ao regime existente.

A estabilização representa a segunda fase, quando a inovação é aplicada em pequenos nichos de mercado desenvolvendo uma trajetória técnica própria e estabilizando regras, passando a existir um projeto de regras dominantes. Embora já exista nessa fase uma construção entre a nova tecnologia e os usuários, a inovação ainda não representa uma ameaça ao regime existente, podendo permanecer dessa forma por décadas. Esse regime existente tem suas atividades alinhadas e coordenadas, mantidas pelos distintos grupos de atores.

$\mathrm{Na}$ terceira fase, a de resistência, há maior inserção das novas tecnologias e concorrência com o regime vigente. Nesse momento se faz necessária a articulação de atores mais poderosos do nicho, em promoverem melhores condições na relação preço/desempenho de suas inovações, bem como impulsioná-las através de capital financeiro, organizacional e político. As condições do regime existente e da paisagem também promovem influência, quando criam janelas de oportunidades para os nichos. Estas janelas aparecem quando problemas surgem confrontando o regime, emergindo assim tensões que rompem as ligações entre os diferentes elementos, até então alinhados e coordenados. São os aspectos internos do nicho e externos 
que abrem oportunidade de concorrência com o regime existente. Esse processo de nicho-acumulação não ocorre de um momento para o outro, mas de forma gradual. A rede, que na primeira fase apresentava ligações inconsistentes, passa a se tornar mais estável e a aumentar o número de elementos heterogêneos (infraestruturas, regulamentos, entusiasmo cultural e práticas do usuário) com ligações mais alinhadas.

A última fase, a de substituição, é a parte do processo que envolvem consideráveis mudanças de uma configuração sociotécnica para outra. É um processo que ocorre não repentinamente, mas de forma gradual, pois a formação de um novo sistema sociotécnico leva tempo. Quando ocorre a substituição o novo sistema já está alinhado com os elementos. Eventualmente esse novo sistema pode instigar desenvolvimentos na paisagem.

\section{MÉTODO}

O presente trabalho caracteriza-se por ser uma pesquisa de abordagem qualitativa. O método adotado foi o estudo de caso, pois se concebe que tal estratégia foi adequada para compreender a trajetória inovadora da vitivinicultura na Campanha Gaúcha. O estudo de caso resulta do anseio por entender fenômenos sociais complexos e proporciona que sejam preservadas nos estudos as características integrais e expressivas da vida real, exigindo assim se ocupar da exposição fiel dos dados coletados (YIN, 2001; 2015).

O objeto de pesquisa está associado aos atores que fazem a produção vitivinícola na Campanha Gaúcha e suas ligações, já a unidade de análise foi definida como o regime sociotécnico da produção vitivinícola da Campanha Gaúcha.

A presente pesquisa dividiu-se em etapa A e B. Na etapa A os procedimentos de coleta de dados envolveram entrevistas abertas, documentos, anotações de campo e observação direta. As entrevistas desta etapa possibilitaram a identificação das fases da vitivinicultura na Campanha Gaúcha. E na etapa B utilizaram-se entrevistas e análise de documentos (fontes secundárias que incluíram documentos de empresas, fotografias, rótulos de vinhos e outros), validações, anotações de campo e observação direta, o que possibilitou a triangulação.

Assim sendo considerou-se um conjunto de elementos teóricos a priori 
que foram apresentados aos entrevistados para que se esgotassem as possibilidades referentes aos tópicos selecionados, sem impelir a liberdade de exposição de suas percepções. O propósito foi o de responder ao objetivo de identificar os fatores sociotécnicos que contribuem para a adoção da vitivinicultura na Campanha Gaúcha, sendo estes os elementos principais que a pesquisa procurou identificar. Considerando que a revisão da literatura deu um indicativo de quais poderiam ser os fatores, elaborou-se uma síntese deles. Esses foram organizados em conjunto com as questões para facilitar a relação entre ambos. Para cada um dos níveis (Nicho, Regime e Paisagem) foram elaboradas perguntas que foram aplicadas a cada uma das fases identificadas na etapa $\mathrm{A}$, ou seja, fase de experimentação, de estabilização e de resistência, conforme Geels (2005).

As entrevistas foram aplicadas aos atores da vitivinicultura da Campanha Gaúcha, definidos atendendo como prioridade seu envolvimento como gestores, coordenadores ou consultores da produção vitivinícola da região. Outra condição que se procurou identificar nos entrevistados, para que fizessem parte da pesquisa, foi o fato de serem naturais da região ou nela residirem há um determinado tempo. $\mathrm{Na}$ impossibilidade de se determinar esse tempo, se considerou o período necessário e estimado que lhes conferisse a condição de manifestar seus conhecimentos, informações e experiências relacionadas à vitivinicultura da Campanha Gaúcha. Dentre os entrevistados havia viticultores, vitivinicultores, técnicos agrícolas, professores universitários da vitivinicultura dentre outros.

Após a coleta de dados da etapa A procedeu-se com a análise de conteúdo (BARDIN, 2004). O resultado foi submetido a três validadores considerados especialistas no tema da vitivinicultura e atuantes na região da Campanha Gaúcha. Adiante, foi realizada a etapa B da pesquisa. Em ambas as etapas considerou-se a necessidade de validação. Compreende-se que a validação consiste em uma revisão pelos próprios participantes e informantes selecionados para o caso. Posteriormente, todo e qualquer registro relevante pode ser incluído na pesquisa (YIN, 2015). 


\section{RESULTADOS}

\subsection{FASES DE EVOLUÇÃO DO REGIME SOCIOTÉCNICO DA PRODUÇÃO VITIVINÍ- COLA NA CAMPANHA GAÚCHA}

De acordo com as entrevistas da etapa A da pesquisa foram apontados três períodos da produção vitivinícola da Campanha Gaúcha, que são: experimentação, estabilização e resistência. Tal procedimento foi possível diante da compreensão de como estão divididas as fases de evolução da vitivinicultura na Campanha Gaúcha, com o depoimento de atores e uma análise através da abordagem de Geels (2005). Assim sendo propõe-se para uma melhor visualização dos resultados do Quadro 1.

Quadro 1. Quadro das Fases de Transição versus Fases da Vitivinicultura conforme atores da Campanha Gaúcha

\begin{tabular}{|c|c|c|c|}
\hline 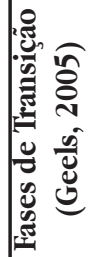 & $\begin{array}{l}\text { Características teóricas } \\
\text { principais (Geels, 2005) }\end{array}$ & $\begin{array}{l}\text { Fases Identi- } \\
\text { ficadas pelos } \\
\text { atores da Vi- } \\
\text { tivinicultura } \\
\text { na Campanha } \\
\text { Gaúcha }\end{array}$ & Características observadas \\
\hline 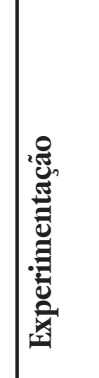 & $\begin{array}{l}\text { Redes ou nichos precários; } \\
\text { Nichos isolados que enfren- } \\
\text { tam situações adversas; Mo- } \\
\text { mento instável, de rede sem } \\
\text { regras claras e dominantes; } \\
\text { Estão à margem do regime } \\
\text { prevalecente; Apresentam } \\
\text { inovações radicais sem ofere- } \\
\text { cer ameaça a esse regime }\end{array}$ & $\begin{array}{l}1^{\mathrm{a}} \text { Fase }(1887 \\
-1969) \\
\end{array}$ & $\begin{array}{l}\text { Registro de produção de vitis vinífera e vinho } \\
\text { (Família Marimon em Bagé e outros nove pro- } \\
\text { dutores em Uruguaiana); Regime prevalecente } \\
\text { na época era a Pecuária; Declínio de produção } \\
\text { de uva em duas ou três décadas; Dificuldade } \\
\text { de competir com outras localidades pela dis- } \\
\text { tância em relação ao mercado consumidor; } \\
\text { Queda de produção (Antracnose e Míldio) }\end{array}$ \\
\hline
\end{tabular}




\begin{tabular}{|c|c|c|c|}
\hline & $\begin{array}{l}\text { O regime tem atividades } \\
\text { alinhadas mantidas por dis- } \\
\text { tintos grupos de atores; O } \\
\text { nicho ainda não é ameaça } \\
\text { para o regime dominante; } \\
\text { Ainda em nichos independen- } \\
\text { tes, é uma fase de constru- } \\
\text { ção, que define regras e abre } \\
\text { caminho para a estabilização; } \\
\text { Desenvolve trajetória própria } \\
\text { que pode estabilizar regras } \\
\text { dominantes. }\end{array}$ & $\begin{array}{l}2^{\mathrm{a}} \text { Fase }(1970 \\
-1999) \\
\\
\end{array}$ & $\begin{array}{l}\text { Estabelecimento de empresas vitivinícolas } \\
\text { vindas de fora e que permanecem na região } \\
\text { até os dias atuais. Tal circunstância reforça a } \\
\text { ideia de estabilização, mesmo sem apresentar } \\
\text { regras dominantes e com uma formação de } \\
\text { nichos ainda independentes; Nessa segunda } \\
\text { fase destaca-se o regime de produção de arroz } \\
\text { e pecuária. }\end{array}$ \\
\hline שֶ: & $\begin{array}{l}\text { Nichos apresentam ligações } \\
\text { mais consistentes e estáveis; } \\
\text { Há inserção de atores mais } \\
\text { poderosos do nicho, com } \\
\text { impulsos de capital financei- } \\
\text { ro, político, organizacional } \\
\text { e promoção das condições } \\
\text { preço/desempenho; Regimes } \\
\text { existentes e paisagem podem } \\
\text { criar janelas de oportunida- } \\
\text { des; Uma rede mais estável } \\
\text { inicia o processo de aumento } \\
\text { de elementos mais hetero- } \\
\text { gêneos (como entusiasmo } \\
\text { cultural, práticas de usuários, } \\
\text { infraestrutura e regulamen- } \\
\text { tos); Processo gradual e de } \\
\text { concorrência com o regime } \\
\text { dominante. }\end{array}$ & $\begin{array}{l}3^{\mathrm{a}} \text { Fase }(2000 \\
- \text { dias })\end{array}$ & $\begin{array}{l}\text { Surgimento de um projeto para a produção } \\
\text { de vitis vinífera entre produtores da região } \\
\text { de Bagé e Vinícola Salton. Por razões diversas } \\
\text { não perdurou com a grande maioria dos pro- } \\
\text { dutores. A condição pode ter servido como } \\
\text { gatilho de ativação que influenciou o sistema; } \\
\text { Criação de associações como a Vinhos da } \\
\text { Campanha. Início do projeto de Indicação de } \\
\text { Procedência dos Vinhos da Campanha e outras } \\
\text { ações para consolidar a marca coletiva dos } \\
\text { Vinhos da Campanha; Influências da paisagem: } \\
\text { necessidade de matéria prima de qualidade } \\
\text { para produzir bons vinhos; Pouco entusiasmo } \\
\text { por parte dos produtores de uva e evidente } \\
\text { expectativa dos vitivinicultores; Vitivinicultores } \\
\text { destacam: fase de recomeço, que veio para } \\
\text { ficar e ainda em etapa inicial; Evidenciam que } \\
\text { não há concorrência com o regime dominan- } \\
\text { te (pecuária, arroz e soja); A vitivinicultura } \\
\text { representa complemento e diversificação da } \\
\text { produção. E não deixa de ser influência desses } \\
\text { demais regimes. }\end{array}$ \\
\hline 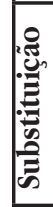 & $\begin{array}{l}\text { Inclui mudanças considerá- } \\
\text { veis na configuração sociotéc- } \\
\text { nica; Um novo sistema pode } \\
\text { promover desenvolvimentos } \\
\text { na paisagem. }\end{array}$ & $\begin{array}{l}\text { Não identifi- } \\
\text { cada }\end{array}$ & \\
\hline
\end{tabular}

Fonte: Elaborado pelos autores 
A partir da compreensão das fases da vitivinicultura da Campanha Gaúcha, foi possível identificar os fatores multiníveis associados à trajetória da vitivinicultura na região.

\subsection{OS FATORES MULTINÍVEIS ASSOCIADOS À TRAJETÓRIA DA VITIVINICULTURA NA CAMPANHA GAÚCHA}

Conforme as entrevistas da segunda etapa da pesquisa, denominada etapa B, e os documentos analisados, foram apontados os fatores multiníveis (Paisagem, Regime e Nicho) das três fases da produção vitivinícola da Campanha Gaúcha.

No Quadro 2 são destacados os fatores identificados no nível da paisagem nas três fases mencionadas. Aos fatores não detectados em uma das fases é atribuída a nomenclatura ausente (A), bem como para aqueles encontrados é atribuído favorável (F) ou desfavorável (D). Cabe ressaltar que no nível da paisagem foi identificado um novo fator, nomeado de recursos naturais, pois faz referência às condições edafoclimáticas favoráveis à vitivinicultura da Campanha Gaúcha. Tais condições foram mencionadas nas três fases investigadas.

Os subfatores encontrados foram analisados e agrupados no intuito de sistematizá-los e alinhá-los com a revisão da literatura. Alguns destes subfatores foram mantidos, como "imigração, interação política e infecção de peronóspora (doença fúngica)", pertencentes, respectivamente, aos fatores de tendência geográfica, ideologias políticas e eventos repentinos com grande impacto.

Já os subfatores "hábito de beber vinho" e "mudança no hábito de beber vinho" foram associados a um único subfator denominado de "hábito de consumo". Do mesmo modo o subfator "aceitação a produção de novas culturas" foi reclassificado como "mudança de comportamento", ambos associados ao fator padrões culturais profundos.

Os subfatores "estabilização do dólar, contenção do processo inflacionário e crise do petróleo" foram agrupados em um único fator denominado de "financeiro"; sendo que "barreira à importação, política de margem máxima para a comercialização dos vinhos e política de abertura comercial" foram agrupados em "comercial". Ambos os novos subfatores são pertencentes ao fator padróes macroeconômicos. 
Quadro 2. Quadro do nível da paisagem com a síntese das fases da vitivinicultura na Campanha Gaúcha, bem como a sistematização dos fatores

\begin{tabular}{|c|c|c|c|c|c|c|}
\hline & & & & & Fases & \\
\hline \multirow{15}{*}{ 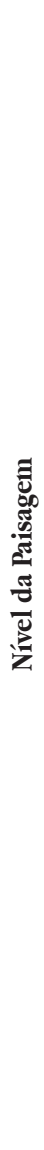 } & Fatores & Subfatores & $\begin{array}{l}\text { Subfatores agru- } \\
\text { pados }\end{array}$ & 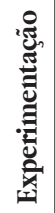 & 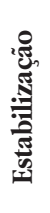 & 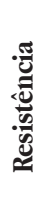 \\
\hline & Tendência demográfica & Imigrantes europeus & Imigração & $\omega$ & $\varangle$ & $\varangle$ \\
\hline & Ideologias políticas & Interação Política & Interação política & $\varangle$ & 山 & $\varangle$ \\
\hline & \multirow{3}{*}{$\begin{array}{l}\text { Padrões culturais pro- } \\
\text { fundos }\end{array}$} & Hábito de beber vinho & \multirow[b]{2}{*}{ Hábito de consumo } & \multirow[t]{2}{*}{ 工 } & \multirow[t]{2}{*}{$\varangle$} & \multirow[t]{2}{*}{ 山 } \\
\hline & & $\begin{array}{l}\text { Mudança no hábito de beber vi- } \\
\text { nho }\end{array}$ & & & & \\
\hline & & $\begin{array}{l}\text { Aceitação a produção de novas } \\
\text { culturas }\end{array}$ & $\begin{array}{l}\text { Mudança de com- } \\
\text { portamento }\end{array}$ & $\varangle$ & $\varangle$ & w \\
\hline & Valores sociais & - & - & $\varangle$ & $\varangle$ & $\varangle$ \\
\hline & \multirow[t]{6}{*}{ Padrões macroeconômicos } & Estabilização do dólar & \multirow[t]{3}{*}{ Financeiro } & \multirow[t]{3}{*}{$\varangle$} & \multirow[t]{3}{*}{ 로 } & \multirow[t]{3}{*}{$\theta$} \\
\hline & & $\begin{array}{l}\text { Contenção do processo inflacio- } \\
\text { nário }\end{array}$ & & & & \\
\hline & & Crise do petróleo & & & & \\
\hline & & Barreira à importação & \multirow[t]{3}{*}{ Comercial } & \multirow[t]{3}{*}{$\varangle$} & \multirow{3}{*}{$\stackrel{+}{9}$} & \multirow[t]{3}{*}{$\varangle$} \\
\hline & & $\begin{array}{l}\text { Política de controle sobre margem } \\
\text { máxima para a comercialização de } \\
\text { vinhos }\end{array}$ & & & & \\
\hline & & Política de abertura comercial & & & & \\
\hline & $\begin{array}{l}\text { Eventos repentinos com } \\
\text { grandes impactos }\end{array}$ & Infecção de peronóspora & $\begin{array}{l}\text { Infecção de pero- } \\
\text { nóspora }\end{array}$ & $\theta$ & $\varangle$ & $\varangle$ \\
\hline & Novo fator: Recursos & Recurso natural & Recurso natural & 工 & I & 工 \\
\hline
\end{tabular}

Legenda: Ausente (A); Favorável (F); Favorável com mais frequência (F+); Desfavorável (D); Desfavorável com mais frequência $(\mathrm{D}+)$.

Fonte: Adaptado de Almeida et al. (2016).

No Quadro 3 são destacados os fatores identificados no nível do regime nas três fases. Os subfatores "linhas férreas, longas distâncias e asfaltamento" foram denominados de "logística"; "disponibilidade de terras e mão de obra relacionada a campo" foram agrupados em "cadeia produtiva". Ambos associados ao fator infraestrutura. 


\section{Quadro 3. Quadro do nível do regime com a síntese das fases da vitivinicultura na Campa-} nha Gaúcha, bem como a sistematização dos fatores

\begin{tabular}{|c|c|c|c|c|c|c|}
\hline & & & & & Fases & \\
\hline \multirow{22}{*}{ 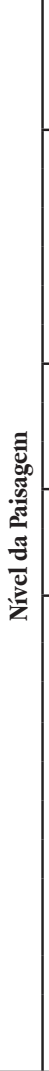 } & Fatores & Subfatores & $\begin{array}{l}\text { Subfatores } \\
\text { agrupados }\end{array}$ & $\begin{array}{l}\text { Experi- } \\
\text { menta- } \\
\text { ção }\end{array}$ & $\begin{array}{l}\text { Estabi- } \\
\text { lização }\end{array}$ & $\begin{array}{l}\text { Resistên- } \\
\text { cia }\end{array}$ \\
\hline & \multirow{6}{*}{ Infraestrutura } & Linhas férreas & \multirow[t]{3}{*}{ Logística } & \multirow[t]{3}{*}{ FD } & \multirow[t]{3}{*}{$\mathrm{F}$} & \multirow[t]{3}{*}{$\mathrm{D}$} \\
\hline & & Longas distâncias & & & & \\
\hline & & Asfaltamento & & & & \\
\hline & & Disponibilidade de terras & \multirow{3}{*}{$\begin{array}{l}\text { Cadeia } \\
\text { produtiva }\end{array}$} & \multirow[t]{3}{*}{ A } & \multirow[t]{3}{*}{ A } & \multirow[t]{3}{*}{$\mathrm{FD}+$} \\
\hline & & Cadeia Produtiva & & & & \\
\hline & & Mão de obra relaciona ao campo & & & & \\
\hline & \multirow{3}{*}{ Artefatos } & Maquinários, ferramentas e equipamentos & \multirow{3}{*}{$\begin{array}{l}\text { Máquinas e } \\
\text { equipamen- } \\
\text { tos }\end{array}$} & \multirow[t]{3}{*}{$\mathrm{F}$} & \multirow[t]{3}{*}{ FD } & \multirow[t]{3}{*}{$\mathrm{F}$} \\
\hline & & Aquisição artefatos de fora da região & & & & \\
\hline & & Aproveitamento de artefatos da agricultura & & & & \\
\hline & \multirow{2}{*}{$\begin{array}{l}\text { Especificidades } \\
\text { da demanda }\end{array}$} & Vinho de melhor qualidade & \multirow[t]{2}{*}{ Consumidor } & \multirow[t]{2}{*}{$\mathrm{F}$} & \multirow[t]{2}{*}{$\mathrm{F}$} & \multirow[t]{2}{*}{$\mathrm{F}+$} \\
\hline & & Espumante & & & & \\
\hline & \multirow{10}{*}{$\begin{array}{l}\text { Potencial } \\
\text { estruturante }\end{array}$} & Normas fiscalizadoras & \multirow{8}{*}{$\begin{array}{l}\text { Regulamen- } \\
\text { tação }\end{array}$} & \multirow[t]{8}{*}{$\mathrm{F}$} & \multirow[t]{8}{*}{$\mathrm{F}++\mathrm{D}$} & \multirow[t]{8}{*}{$\mathrm{F}++\mathrm{D}+$} \\
\hline & & Mecosul & & & & \\
\hline & & Cadastro vitícola & & & & \\
\hline & & Lei do vinho & & & & \\
\hline & & Decreto $\mathrm{n}^{\circ} 8.198$ & & & & \\
\hline & & Ministério da agricultura & & & & \\
\hline & & Carga tributária & & & & \\
\hline & & $\begin{array}{l}\text { Legislação eficiente e fiscalização efetiva ao con- } \\
\text { trabando }\end{array}$ & & & & \\
\hline & & Distribuição de videiras & \multirow{2}{*}{$\begin{array}{l}\text { Dominância } \\
\text { tecnológica }\end{array}$} & \multirow[t]{2}{*}{$\mathrm{F}$} & \multirow[t]{2}{*}{$\mathrm{F}$} & \multirow[t]{2}{*}{ A } \\
\hline & & $\begin{array}{l}\text { Tendência da indústria agroalimentar interna- } \\
\text { cional }\end{array}$ & & & & \\
\hline & Dinamismo da & Conhecimento trazido pelos imigrantes & Experiências & $\mathrm{F}$ & $\mathrm{F}$ & $\mathrm{F}+$ \\
\hline & produção do & Conhecimento e informação & empíricas & & & \\
\hline & & Mão de obra das empresas & & & & \\
\hline & & Viveiristas & & & & \\
\hline & & Primeira estação experimental & Científico & $\mathrm{F}$ & $\mathrm{F}+$ & $\mathrm{F}+$ \\
\hline & & Publicações de interesse agrícola & & & & \\
\hline & & Tecnologia da vitis vinifera & & & & \\
\hline & & Pesquisas feitas pelas empresas & & & & \\
\hline & & Bacharelado em enologia & & & & \\
\hline & & Tecnologias & & & & \\
\hline
\end{tabular}

Legenda: Ausente (A); Favorável (F); Favorável com mais frequência (F+); Desfavorável (D); Desfavorável com mais frequência $(\mathrm{D}+)$.

Fonte: Adaptado de Almeida et al. (2016). 
Os subfatores "máquinas, ferramentas e equipamentos", "aquisição de artefatos de fora da região" e "aproveitamento de artefatos da agricultura" foram agrupados em "máquinas e equipamentos" e todos associados ao fator artefatos. Do mesmo modo, os subfatores "vinho de melhor qualidade" e "espumante" foram agrupados em "consumidor" dentro do fator especificidade da demanda. Já em potencial estruturante os subfatores "distribuição de videiras, normas fiscalizadoras, Mercosul, Cadastro Vitícola, Lei do Vinho, Decreto $n^{\circ}$ 8.198, Ministério da Agricultura, carga tributária, legislação eficiente e fiscalização efetiva ao contrabando" foram agrupados como "regulamentações". Já "Tendência da indústria agroalimentar internacional" foi renomeado como "dominância tecnológica". Ambos os dois novos subfatores associados ao fator potencial estruturante.

No dinamismo da produção do conhecimento, os subfatores como "conhecimentos trazidos pelos imigrantes", "mão de obra das empresas", "conhecimento e informação" e "viveiristas" foram sintetizados em "experiências empíricas". Sendo que os subfatores "primeira estação experimental, publicações de interesse agrícola, tecnologia da vitis vinifera, Bacharelado em Enologia e tecnologias" foram identificados como "científico".

No Quadro 4 são destacados os fatores identificados no nível do nicho nas três fases. Assim como no nível da paisagem, no nível de nicho também foi identificado um novo subfator denominado "limitação financeira" e associado ao fator recursos.

No fator identificação de oportunidades e ameaças o subfator "clientes" agrupou "participação dos vinhos em concursos" e "retorno dos clientes". O subfator "fornecedores" não foi reclassificado. Contudo ao subfator "rede" foram agrupados "instituições representativas do setor, cursos, eventos, mão de obra com formação específica, associações, Estatuto da Associação Vinhos da Campanha e ambiente dinâmico". Ao subfator "pesquisa" foram agrupados "centros de pesquisa, contato com produtores, assim como instituições de ensino e consultoria".

No fator aproveitamento de oportunidades, ao subfator "fomento à criatividade" foi reunido "troca de informações e conhecimento entre produtores", "visitas técnicas" e "grupo informal". Já ao subfator "complementaridade de ativos" foi atribuída a "aproximação com empresas mais inovadoras", "compras em conjunto 
de insumos", "Bacharelado em Enologia", "aproximação das microrregiões" e "aproximação com outros setores".

No fator reconfiguração os subfatores iniciais também foram agrupados em apenas dois. No subfator "transferência de conhecimento" está agrupada a "não proteção do know-bow", "proximidade com novas tecnologias", "proximidade com clientes e mercados", "conhecimento transferido aos viticultores", "proximidade com fornecedores", "contratação de especialistas e consultores", "ação conjunta com instituições de pesquisa e especialistas e consultores".

Nas barreiras individuais permaneceu a "acomodação e proteção à autoimagem". Nas barreiras organizacionais permaneceu a "dificuldade de acesso ao conhecimento e informação". Em características dos empreendedores e empreendimentos utilizou-se o subfator "característica empreendedora" onde se incluiu os subfatores iniciais "característica empreendedora" e "motivação". 
Quadro 4. Quadro do nível do regime com a síntese das fases da vitivinicultura na Campanha Gaúcha, bem como a sistematização dos fatores

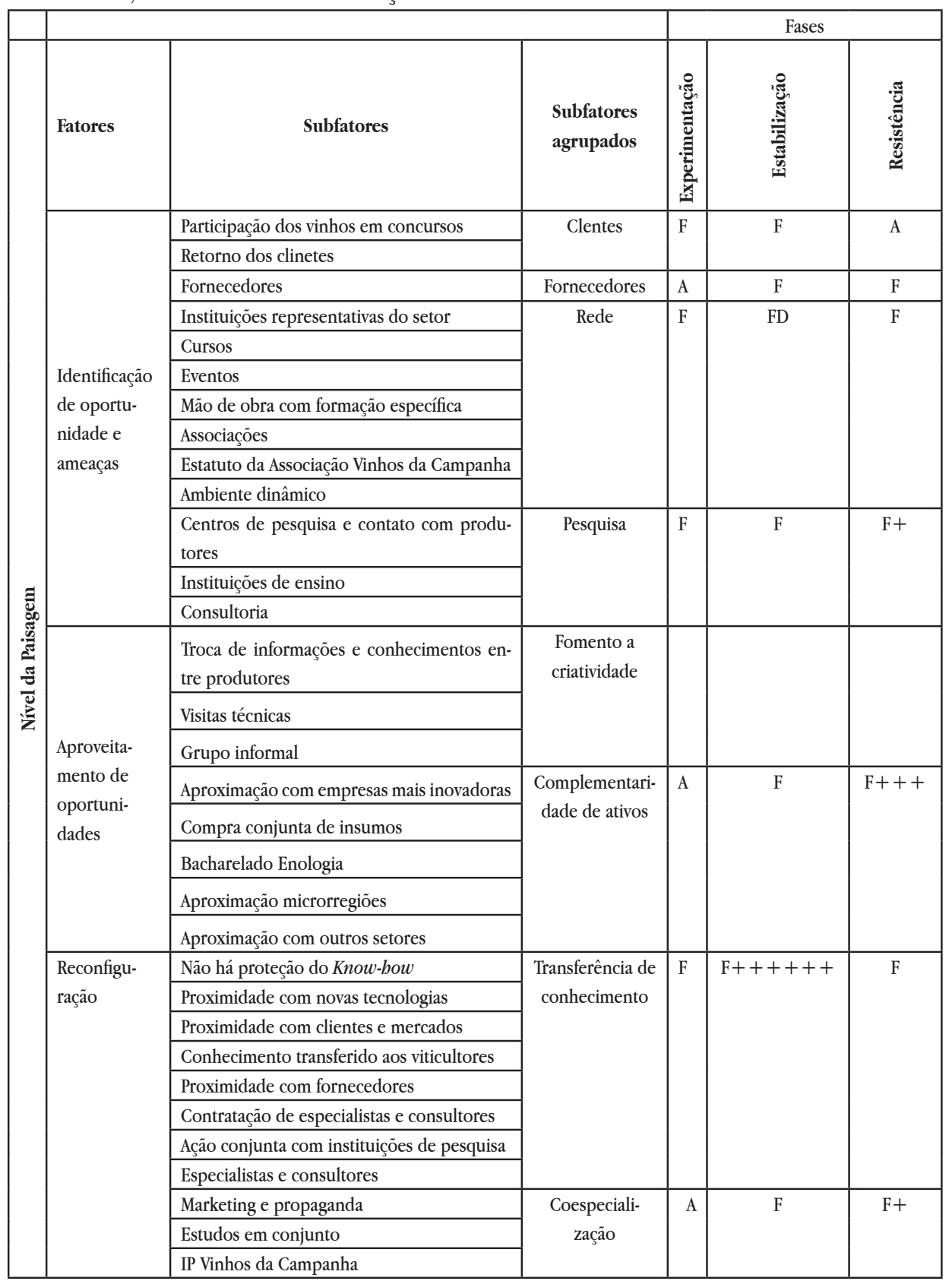




\begin{tabular}{|c|c|c|c|c|c|}
\hline $\begin{array}{l}\text { Barreiras } \\
\text { individuais }\end{array}$ & Acomodação e proteção à autoimagem & & A & $\mathrm{D}$ & $\mathrm{D}$ \\
\hline $\begin{array}{c}\text { Barreiras } \\
\text { organizacio- } \\
\text { nais }\end{array}$ & $\begin{array}{l}\text { Dificuldade de acesso ao conhecimento e } \\
\text { informação }\end{array}$ & & $\mathrm{D}$ & A & A \\
\hline $\begin{array}{l}\text { Barreiras } \\
\text { externas }\end{array}$ & Ausência de barreiras externas & & A & A & A \\
\hline \multirow{2}{*}{$\begin{array}{l}\text { Caracterís- } \\
\text { ticas dos } \\
\text { empreen- } \\
\text { dedores e } \\
\text { empreendi- } \\
\text { mentos }\end{array}$} & Caracterìstica empreendedora & \multirow[t]{2}{*}{$\begin{array}{l}\text { Caracterìstica } \\
\text { empreendedora }\end{array}$} & & & \\
\hline & Motivação & & & & \\
\hline $\begin{array}{l}\text { Novo fator: } \\
\text { Recursos }\end{array}$ & Limitação financeita & & A & A & $\mathrm{D}$ \\
\hline
\end{tabular}

Legenda: Ausente (A); Favorável (F); Favorável com mais frequência (F+); Desfavorável (D); Desfavorável com mais frequência $(\mathrm{D}+)$.

Fonte: Adaptado de Almeida et al. (2016).

\section{CONSIDERAÇÕES FINAIS}

O trabalho apresentado teve como objetivo analisar os fatores sociotécnicos que contribuem para a trajetória inovadora da produção vitivinícola na Campanha Gaúcha. Para tanto, utilizou-se como meio de análise o que nos estudos de inovação é nomeado de transição sociotécnica. Dentro dessa análise de transição utilizou-se a abordagem teórica PMN para se proceder com a compreensão da adoção da vitivinicultura na Campanha, com atual relevância na produção de vitis vinifera e elaboração de vinhos finos no Brasil.

Os resultados corroboraram as proposições 1 e 2 , assim como possibilitaram uma sistematização dos fatores multiníveis associados aos processos de transição sociotécnica. Somam-se a estes esforços a identificação de um novo fator no nível da paisagem e do nicho, ambos associados à ideia de recursos. O primeiro ligado aos recursos do território e o segundo ligado aos recursos dos atores. Cabe salientar que muitos fatores se apresentaram ausentes nas fases de cada nível por serem mencionados em uma fase e não serem em outra.

Como uma possibilidade de estudos futuros sugere-se a utilização dos fa- 
tores identificados nas fases de evolução e a avaliação se estes fatores têm a mesma importância para a evolução da trajetória sociotécnica. Recomenda-se que a investigação seja promovida através de representantes da vitivinicultura, contudo com atores que representem cada um dos níveis: paisagem, regime e nicho.

Uma limitação importante do trabalho se refere à investigação de períodos de passado longínquo, pois a necessidade de triangulação dos dados demanda muito tempo. Os estudos de transição envolvem períodos longos, mas esses estudos demonstram relevância nas pesquisas científicas sendo necessário encontrar o método mais adequado para que a investigação não demande tanto tempo pela dedicação que exige. De qualquer modo, a pesquisa traz uma contribuição para a compreensão de quais são estes fatores que podem estar envolvidos nestes processos de mudança.

\section{REFERÊNCIAS}

ALMEIDA, G. M. A.; DIAS, M. F. P.; MAEHLER, A. E. Processo de inovação: estudo de caso da adoção do sistema de produção de arroz orgânico vinculada ao NEMA. Revista de Administração da UFSM, Santa Maria, v. 9, n. 02, p. 262-279, Abr./Jun. 2016.

BARDIN, L. Análise de conteúdo. $3^{\mathrm{a}}$ ed. Lisboa: Edições 70, 2004.

BIJKER, W. E. Of Bicycles, Bakelites, and Bulbs: Toward a Theory of Sociotechnical Change. Cambridge, Mass: MIT Press, 1995.

BULHÕES, F. M. Conhecimento e inovação no manejo de sistemas agroflorestais por citricultores ecológicos no Vale do Caí. Tese (Doutorado em Desenvolvimento Rural) - Faculdade de Ciências Econômicas da Universidade Federal do Rio Grande do Sul. Porto Alegre: UFRGS, 2011.

DIAS, M. F. P.; PEDROZO, E. A.; SILVA, T. N. D. The innovation process as a complex structure with multilevel rules. Journal of Evolutionary Economics, v. 24, n. 5, p. 1067-1084, 2014.

ELZEN, B.; GEELS, F. W.; BARBARA, C. L.; MIERLO, V. Normative contestation in 
transitions 'in the making': Animal welfare concerns and system innovation in pig husbandry. Research Policy, v. 40, p. 263-275, 2011.

FALCADE, I. A paisagem como representação espacial: A paisagem vitícola como símbolo das indicações de procedência de vinhos das regiões Vale dos Vinhedos, Pinto bandeira e Monte Belo (Brasil). 2011. 309 f. Tese (Doutorado em Geografia). Programa de Pós-Graduação em Geografia. Porto Alegre: IGEO, UFRGS, 2011.

GEELS, F. W. Technological transitions as evolutionary reconfiguration processes: a multi-level perspective and a case-study. Research Policy, v. 31, n. 8-9, p. 1257 1274, 2002.

GEELS, F. W. The dynamics of transitions in socio-technical systems: a multi-level analysis of the transition pathway from horse-drawn carriages to automobiles (18601930). Technology Analysis \& Strategic Management, v. 17, n. 4, p. 445-476, 2005.

GEELS, F. W. The multi-level perspective on sustainability transitions: responses to seven criticisms. Environmental Innovation and Societal Transitions, v. 1, n. 1, p. 24-40, 2011.

GEELS, F. W.; SCHOT, J. Typology of sociotechnical transition pathways. Research Policy, v. 36, n. 3, p. 399-417, 2007.

GENUS, A.; COLES, A. M. Rethinking the multi-level perspective of technological transitions. Research Policy, v. 37, p. 1436-1445, 2008.

HOFMAN, P. S.; ELZEN, B. Exploring system innovation in the electricity system through sociotechnical scenarios. Technology Analysis \& Strategic Management, v. 22, n. 6, 653-670, Aug. 2010.

LACHMAN, D. A. A survey and review of approaches to study transitions. Energy Policy, v. 58, p. 269-276, Jul. 2013.

LOORBACH, D. Transition Management: New Mode of Governance for Sustainable Development, International Books, Utrecht, 2007. 
MARKARD, J.; RAVEN, R.; TRUFFER, B. Sustainability transitions: An emerging field of research and its prospects. Research Policy, v. 41, n. 6, p. 955-967, Jul. 2012.

MARQUES, F. C. Velhos conhecimentos, novos desenvolvimentos: transições no regime sociotécnico da agricultura: a produção de novidades entre agricultores produtores de plantas medicinais no sul do Brasil. Tese (Doutorado em Desenvolvimento Rural) - Faculdade de Ciências Econômicas da Universidade Federal do Rio Grande do Sul. Porto Alegre: UFRGS, 2009.

MENDONÇA, M. A. F. C. Sistemas agroalimentares e sustentabilidade: sistemas de certificação da produção orgânica no Sul do Brasil e na Holanda. Tese (Doutorado em Desenvolvimento Rural) - Faculdade de Ciências Econômicas da Universidade Federal do Rio Grande do Sul. Porto Alegre: UFRGS, 2015.

MILLER, R.; FLORICEL, S. Games of Innovation: a new theoretical perspective. International Journal of Innovation Management, v. 11, n. 1, p. 35, 2007.

NELSON, R. R.; WINTER, S. G. An evolutionary theory of economic change. Cambridge, M. A.: Harvard Univ. Press, 1982.

NICOLA, M. P. Espaço protegido e desenvolvimento rural: Práticas e trajetórias na pecuária familiar da Região Centro Sul do Rio Grande do Sul. Tese (Doutorado em Desenvolvimento Rural) - Faculdade de Ciências Econômicas da Universidade Federal do Rio Grande do Sul. Porto Alegre: UFRGS, 2015.

NONAKA, I.; TAKEUCHI, H. The Knowledge Creating Company. New York: Oxford University Press, 1995.

NONAKA, I.; TAKEUCHI, H. Gestão do conhecimento. Porto Alegre: Bookmann, 2008.

NYKVIST, B.; WHITMARSH, L. A multi-level analysis of sustainable mobility transitions: Niche development in the UK and Sweden. Technological Forecasting \& Social Change. v. 75, p. 1373-1387 (2008).

OROSKI, F. de A. Espaço protegido e desenvolvimento rural: Práticas e trajetórias na pecuária familiar da Região Centro Sul do Rio Grande do Sul. Tese 
(Doutorado em Processos Químicos e Bioquímicos) - Escola de Química da Universidade Federal do Rio de Janeiro. Rio de Janeiro: UFRJ, 2013.

RAVEN, R. P. J. M. Implementation of manure digestion and co-combustion in the Dutch electricity regime: a multi-level analysis of market implementation in the Netherlands. Energ y Policy, n. 32, p. 29-39, 2004.

ROOTMANS, J.; KEMP, R.; ASSELT, M. More evolution than revolution: Transition management. Foresight. v. 3, n. 1, Feb. 2001.

SMITH, A. Translating Sustainabilities Between Green Niches and Socio-Technical Regimes. Technology Analysis \& Strategic Management, v. 19, n. 4, p. 427-450, July 2007.

TEECE, D. J. Explicating dynamic capabilities: The nature and microfoundations of (sustainable) enterprise performance. Strategic Management Journal, v. 28, n. 13, p. 1319-1350, Dec. 2007.

TORRES, A. C.; MARTINS, J. V. B.; OROSKI, F. A.; ALVES, F. C. Transição de sistemas tecnológicos: o desafio da inclusão das matérias-primas renováveis na indústria química brasileira. In: CONGRESSO LATINO-IBEROAMERICANO DE GESTÃO DA TECNOLOGIA, 16., 2015. Anais [...]. Porto Alegre: ALTEC, 2015.

VAN DRIEL, H.; SCHOT, J. Adical Innovation as a Multilevel Process: Introducing froating grain elevators in the Porto of Rotterdam. Technology and Culture, v. 46, n. 1, January, 2005.

VERBONG, G. P. J.; GEELS, F. W. The ongoing energy transition: lessons from a sócio-technical, multi-level analysis of the Dutch electricity system (1960-2004). Energy Policy, v. 35 (2), p. 1025-1037, 2007.

VERBONG, G. P. J.; GEELS, F. W. Exploring sustainability transitions in the electricity sector with socio-technical pathways Technological. Forecasting \& Social Change, v. 77, p. 1214-1221, 2010.

YIN, R. K. Estudo de caso: planejamento e métodos. Tradução Cristina Matheus 
Herrera. 5. ed. Porto Alegre: Bookman, 2015.

ZAHRA, S. A.; GEORGE, G. A. Absorptive capacity: a review, reconceptualization, and extension. Academy of Management Review, New York, v. 27, n. 2, p. 185-203, apr. 2002.

Recebido em: 10/06/2017

Aceito em: 24/05/2018 